\title{
ORIGINAL ARTICLE Peripheral administration of lactate produces antidepressant-like effects
}

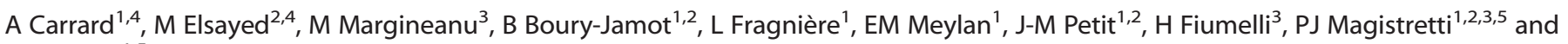 \\ J-L Martin ${ }^{1,5}$
}

In addition to its role as metabolic substrate that can sustain neuronal function and viability, emerging evidence supports a role for L-lactate as an intercellular signaling molecule involved in synaptic plasticity. Clinical and basic research studies have shown that major depression and chronic stress are associated with alterations in structural and functional plasticity. These findings led us to investigate the role of L-lactate as a potential novel antidepressant. Here we show that peripheral administration of L-lactate produces antidepressant-like effects in different animal models of depression that respond to acute and chronic antidepressant treatment. The antidepressant-like effects of L-lactate are associated with increases in hippocampal lactate levels and with changes in the expression of target genes involved in serotonin receptor trafficking, astrocyte functions, neurogenesis, nitric oxide synthesis and CAMP signaling. Further elucidation of the mechanisms underlying the antidepressant effects of L-lactate may help to identify novel therapeutic targets for the treatment of depression.

Molecular Psychiatry (2018) 23, 392-399; doi:10.1038/mp.2016.179; published online 18 October 2016

\section{INTRODUCTION}

Over the past years, evidence has accumulated indicating that glial cells are involved in the pathophysiology of major depression. In particular, reductions in the number and density of glial cells have been observed in different frontolimbic brain regions of depressed patients. ${ }^{1}$ Decreases in glial cell density are accompanied by changes in the expression of several astrocytic markers in frontolimbic cortical regions and subcortical brain areas including the hippocampus of depressed patients, suggesting that astrocyte dysfunction contributes to the pathogenesis of major depressive disorder. ${ }^{1,2}$

Astrocytes are support cells necessary to ensure neuronal functioning and viability. In this context, astrocytes are involved in essential brain mechanisms and functions including energy metabolism, $\mathrm{K}^{+}$buffering, neurotransmitter recycling, neurogenesis, neuronal plasticity and synaptic transmission. ${ }^{3,4}$ With regard to energy metabolism, astrocytes have a central role in brain energy production, delivery, utilization and storage. In particular, astrocytes respond to glutamatergic activation by increasing the rate of glucose utilization and the release of lactate, ${ }^{5}$ a metabolic substrate that can support neuronal energy demands. Another metabolic feature of astrocytes with respect to glucose metabolism is that they are the only brain cell type capable of storing glucose as glycogen. Of particular relevance to depression, astrocyte glycogen levels are regulated by noradrenaline and serotonin. ${ }^{6}$ In addition to fulfilling the metabolic needs of astrocytes, ${ }^{7}$ astrocytic glycogen breakdown typically results in the production and release of lactate, ${ }^{7}$ which can sustain neuronal function and viability. Taken together, these findings establish that both glycogen mobilization and increased glycolysis lead to the production and release of lactate by astrocytes, highlighting the important role of this monocarboxylate in brain energetics.

In addition to its role as a neuronal energy substrate, an increasing number of studies indicate that lactate fulfills a signaling role in the brain (for review see Mosienko et $a l^{8}$ ). For instance, studies have shown that the transfer of lactate from astrocytes to neurons is necessary for long-term memory formation ${ }^{9}$ and for cocaineinduced long-lasting behavioral effects. ${ }^{10}$ Interestingly, the role of lactate in these synaptic plasticity mechanisms is independent of its function as an energy source.

Analysis of the molecular mechanisms underlying the role of lactate in synaptic plasticity has revealed that L-lactate increases the expression of plasticity-related genes including Arc, c-Fos, Zif268 and $B D N F$ in cortical neurons. ${ }^{11}$ Interestingly, evidence indicates that these synaptic plasticity genes are involved in the pathophysiology and treatment of depression. For instance, the expression of Arc and Zif268 is decreased in the prefrontal cortex of depressed subjects and in the medial prefrontal cortex of mice subjected to chronic social defeat stress. ${ }^{12}$ In addition, the expression of Zif268 and c-fos is regulated by different classes of antidepressants in several brain areas. ${ }^{13,14}$ Post-mortem analysis of brain-derived neurotrophic factor expression has shown increased levels in the rodent hippocampus and in the hippocampus of depressed subjects following antidepressant administration. ${ }^{15,16}$

Studies in humans and animal models have shown that depression and chronic stress are associated with alterations in synaptic plasticity that are characterized by a decreased number of axospinous synapses and by a reduced expression of synapserelated genes in the prefrontal cortex and hippocampus. ${ }^{17,18}$ Growing evidence also indicates that reversal of synaptic deficits by antidepressants involves enhanced expression of

${ }^{1}$ Center for Psychiatric Neurosciences, Department of Psychiatry, Lausanne University Hospital, Lausanne, Switzerland; ${ }^{2}$ Brain Mind Institute, Ecole Polytechnique Fédérale de Lausanne, Lausanne, Switzerland and ${ }^{3}$ King Abdullah University of Science and Technology (KAUST), BESE Division, Thuwal, Saudi Arabia. Correspondence: Professor PJ Magistretti or Dr J-L Martin, Center for Psychiatric Neurosciences, Department of Psychiatry, Lausanne University Hospital, Lausanne, Switzerland.

E-mail: pierre.magistretti@kaust.edu.sa or jean-luc.martin@unil.ch

${ }^{4}$ These authors are co-first authors.

${ }^{5}$ These authors are co-last authors.

Received 12 April 2016; revised 18 August 2016; accepted 26 August 2016; published online 18 October 2016 
plasticity-related genes. ${ }^{17}$ Collectively, these observations led us to hypothesize that, by increasing the expression of plasticity-related genes, L-lactate may produce antidepressant-like effects.

The aim of this study was to examine the effects of peripheral L-lactate administration on depressive-like behavior. Here we show that acute and chronic peripheral administration of L-lactate produces antidepressant-like effects. At the cellular level, peripheral L-lactate administration increases hippocampal extracellular L-lactate levels and regulates downstream signaling molecules and target genes that may contribute to its antidepressant action.

\section{MATERIALS AND METHODS}

Methods not described here can be found in Supplementary Information.

\section{Forced swim test}

The forced swim test (FST) was performed as described previously. ${ }^{19}$ Briefly, C57BI/6 mice were placed in a $5 \mathrm{~L}$ cylindrical container filled to a depth of $15 \mathrm{~cm}$ with water $\left(23-25^{\circ} \mathrm{C}\right)$. A $10 \mathrm{~min}$ swim test session was videotaped, and time spent immobile (defined as minimal movements necessary to stay afloat) was scored by an individual blind to the drug treatment. Time spent immobile during the swim session was scored during $4 \mathrm{~min}$ after the initial $2 \mathrm{~min}$. Mice were intraperitoneally injected with vehicle $(0.9 \% \mathrm{NaCl})$, L-lactate $\left(1 \mathrm{~g} \mathrm{~kg}^{-1}\right)$, D-lactate $\left(1 \mathrm{~g} \mathrm{~kg}^{-1}\right)$ or desipramine $\left(20 \mathrm{mg} \mathrm{kg}^{-1}\right)$ and tested $1 \mathrm{~h}$ later. The treatments were randomly assigned.

\section{Repeated open-space FST}

The repeated open-space FST was performed as described previously. ${ }^{20}$ Swimming was carried out for $15 \mathrm{~min}$ per session in rat cages $(43 \mathrm{~L} \times 22 \mathrm{~W} \times 23$ $\mathrm{H}$, in $\mathrm{cm}$ ) filled with water to a depth of $15 \mathrm{~cm}$ at $34 \pm 1{ }^{\circ} \mathrm{C}$. Mice swam individually for $15 \mathrm{~min}$ per day on 4 consecutive days before intraperitoneal administration of vehicle $(0.9 \% \mathrm{NaCl})$, L-lactate $\left(1 \mathrm{~g} \mathrm{~kg}^{-1}\right)$, D-lactate $\left(1 \mathrm{~g} \mathrm{~kg}^{-1}\right)$ or desipramine $\left(20 \mathrm{mg} \mathrm{kg}^{-1}\right)$ and then two times a week until $\sim 3$ weeks had passed. Mice were allocated into the four experimental groups after the fourth day of pretest. Animals with a decreased immobility time during the pretest were excluded (two animals). Water was changed after three mice had swum to maintain a constant water temperature. Swim sessions were videotaped from above and immobility was scored by an individual blind to the drug treatment. Immobility was defined as the absence of movements, except those necessary to keep the head above water.

\section{Corticosterone treatment}

An emulsion of corticosterone $\left(4 \mathrm{mg} \mathrm{ml}^{-1}\right)$ was prepared by mixing corticosterone with $2 \%$ dimethyl sulfoxide (DMSO) in sesame oil. Mice received a single subcutaneous injection of corticosterone $\left(20 \mathrm{mg} \mathrm{kg}^{-1}\right.$; Zhao et $\left.a l^{21}\right)$ or vehicle (2\% DMSO in sesame oil) on each of every 21 consecutive days. In addition, corticosterone-treated mice were given intraperitoneal injections of vehicle $(0.9 \% \mathrm{NaCl})$, L-lactate $\left(1 \mathrm{~g} \mathrm{~kg}^{-1}\right)$, D-lactate $\left(1 \mathrm{~g} \mathrm{~kg}^{-1}\right)$ or desipramine $\left(20 \mathrm{mg} \mathrm{kg}^{-1}\right)$ daily for 21 days. The treatments were randomly assigned. At $24 \mathrm{~h}$ after the last injection, mice were tested in the FST (see above), tail suspension test and saccharin preference test. For the tail suspension test, mice were individually suspended by the tip of the tail with an adhesive tape on an horizontal metal bar at a height of $\sim 34 \mathrm{~cm}$. Mice were videotaped during $5 \mathrm{~min}$ and total immobility time was manually recorded. For the saccharin preference test, mice were singly housed in standard cages $24 \mathrm{~h}$ after the last drug administration. Testing was initiated by presenting two bottles (randomized to right versus left): one filled with water and the other one with a $0.02 \%$ saccharin solution. Bottles were weighed before and $48 \mathrm{~h}$ after saccharin access. Total consumption was calculated and data were expressed as the percentage of saccharin preference (ratio of the volume of saccharin consumed to the total volume of fluid consumed).

\section{RESULTS}

Increased hippocampal lactate levels after peripheral L-lactate administration

As an initial step in assessing the potential antidepressant effects of lactate, we established that peripheral lactate administration increased lactate concentration in the hippocampus, a key limbic
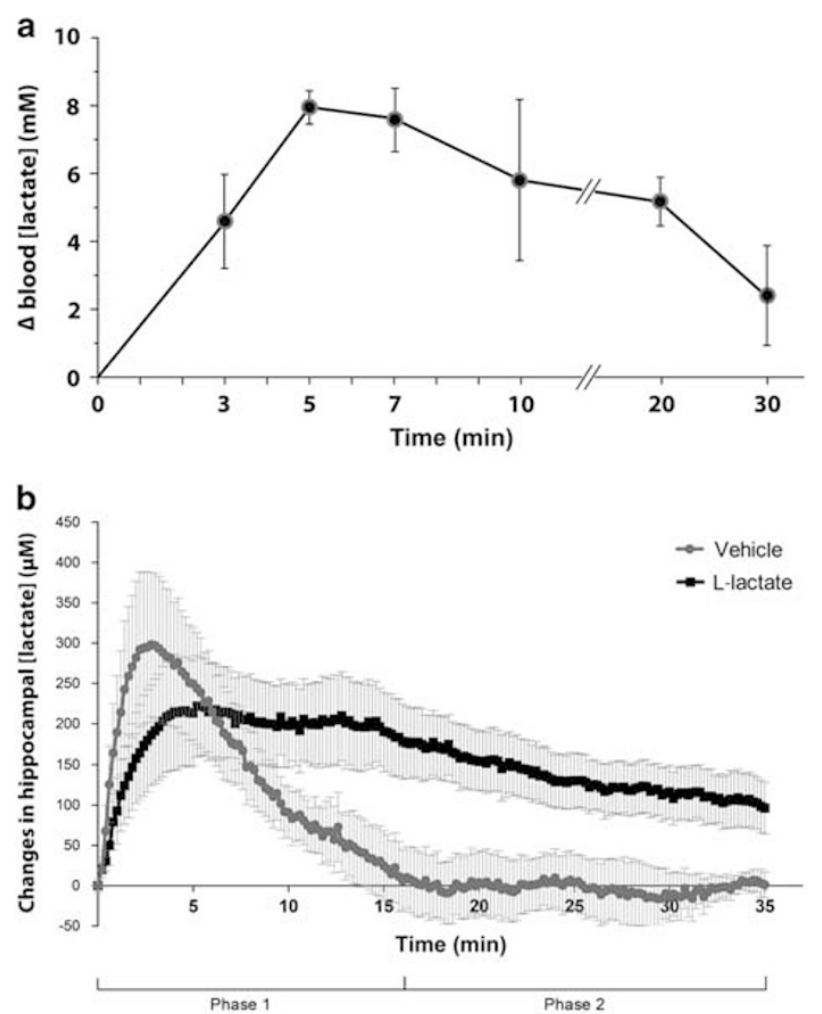

C
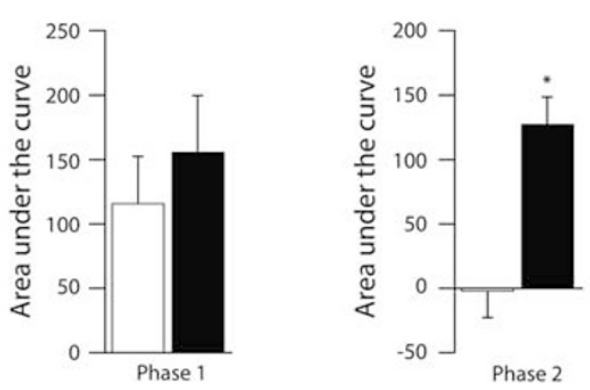

Figure 1. Peripheral administration of L-lactate increases extracellular L-lactate concentration in the hippocampus. (a) Intraperitoneal injection of L-lactate $\left(1 \mathrm{~g} \mathrm{~kg}^{-1}\right)$ increases blood lactate concentration. Data are the mean \pm s.e.m., $n=5$ mice per group. (b) Intraperitoneal L-lactate administration results in a significant elevation of hippocampal extracellular L-lactate concentration during phase 2, as measured with an L-lactate biosensor inserted within the hippocampus. Results are the mean \pm s.e.m., $n=5$ mice per group. (c) Data in (b) expressed as area under the curve during phases 1 and 2. ${ }^{*} P<0.05$ compared with vehicle-treated mice (Student's $t$-test).

structure implicated in the pathophysiology of major depression. Intraperitoneal injection of L-lactate $\left(1 \mathrm{~g} \mathrm{~kg}^{-1}\right)$, the physiological enantiomer of lactate, induced a rapid and sustained increase in blood lactate level that reached a plateau 5 min after injection and returned to near-baseline levels within $30 \mathrm{~min}$ (Figure 1a). The maximum increase in blood lactate concentration is within the same range of blood lactate levels measured in rodents during exercise. ${ }^{22,23}$ Using an L-lactate selective biosensor inserted within the hippocampus, we found that intraperitoneal L-lactate administration resulted in a significant increase of $\sim 200 \mu \mathrm{m}$ in extracellular lactate concentration that slowly declined to $\sim 100 \mu \mathrm{m}$ within $35 \mathrm{~min}$ (Figure $1 \mathrm{~b}$ ). The rapid and transient elevation of extracellular lactate concentration following vehicle injection (phase 1; Figure 1b), which is not statistically different from that induced by L-lactate (phase 1; Figure 1c), is likely to be 
caused by injection stress as it has been shown that stress increases extracellular lactate levels in rodent hippocampus. ${ }^{24,25}$ However, a significant elevation of hippocampal extracellular lactate concentration was observed during phase 2 following peripheral L-lactate administration compared with vehicle injection (Figures $1 \mathrm{~b}$ and $\mathrm{c}$ ).

\section{Antidepressant-like effects induced by acute administration of L-lactate}

The effect of peripheral L-lactate administration on depressive-like behavior was assessed in animal models that respond to both acute and chronic antidepressant treatment. The effect of peripheral administration of L-lactate was first measured using the FST, a well-established behavioral despair paradigm used to screen compounds for putative antidepressant activity. ${ }^{26} \mathrm{~A}$ single peripheral injection of L-lactate $\left(1 \mathrm{~g} \mathrm{~kg}^{-1}\right.$, intraperitoneally) reduced immobility in the FST to a similar extent as desipramine (Figure 2a), whereas the enantiomer D-lactate had no effect (Supplementary Figure 1a). Importantly, mice injected with L-lactate did not display alterations in locomotor activity and neuromuscular strength as shown in the open-field and grip strength tests (Supplementary Figure 2). Collectively, these data indicate that acute peripheral administration of L-lactate produces an antidepressant-like behavioral response in the FST.

Regulation of signaling molecules and target genes by acute L-lactate administration

As a first step towards elucidating how L-lactate induces antidepressant-like behavior, we sought to identify the signaling pathways and target genes that are regulated in the hippocampus after a single peripheral administration of L-lactate.

Because glycogen synthase kinase-3 (GSK3) is implicated in the etiology and treatment of mood disorders, ${ }^{27}$ we examined the effect of L-lactate on phosphorylation level of GSK3. Phosphorylation levels of both GSK3a and GSK3 $\beta$ in the hippocampus were reduced $1 \mathrm{~h}$ after a single intraperitoneal injection of L-lactate $\left(1 \mathrm{~g} \mathrm{~kg}^{-1}\right)$ (Figures $2 \mathrm{~b}$ and $\mathrm{c}$ ). Accumulating evidence also supports a role of the transcription factor CAMP response element-binding protein (CREB) in the pathophysiology and treatment of depression. ${ }^{28} \mathrm{We}$ therefore examined whether L-lactate regulates the phosphorylation level of CREB at Ser133. A single peripheral L-lactate administration was found to reduce phospho-CREB levels in the hippocampus $1 \mathrm{~h}$ after injection (Figure 2d).

To further characterize the molecular mechanisms of L-lactate action, we sought to identify target genes that are rapidly regulated by L-lactate in the hippocampus. We observed that a single peripheral injection of L-lactate upregulates the expression of Arc mRNA in the hippocampus (Figure 2e). Because previous studies suggest that inflammation increases the risk of developing major depression, ${ }^{29}$ we examined whether L-lactate regulated the expression of cyclooxygenase-2 (COX-2), an enzyme responsible for the formation of prostaglandins. Mice that received a single intraperitoneal injection of L-lactate showed a decreased expression of COX-2 mRNA in the hippocampus (Figure 2f). Earlier studies have shown that inhibition of nitric oxide synthase or NO production induces antidepressant-like effects in the FST. ${ }^{30}$ In this context, we determined whether L-lactate regulated the expression of nitric oxide synthase 1 (NOS1), the neuronal isoform of NOS. We found that NOS1 mRNA levels were decreased in the hippocampus of mice that received $1 \mathrm{~h}$ earlier a single peripheral administration of L-lactate (Figure $2 \mathrm{~g}$ ).

\section{Antidepressant-like effects produced by chronic L-lactate administration}

We further investigated the antidepressant-like behavioral effects of L-lactate in the corticosterone model of depression. Previous studies have reported that chronic administration of corticosterone in rodents produces behavioral and neurobiological alterations that mimic symptoms and neurobiological changes associated with human depression. ${ }^{31}$ We therefore examined the effect of L-lactate on depressive-like behavior induced by chronic administration of corticosterone. Similarly to desipramine, we found that chronic administration of L-lactate (Figures 3a and b), but not D-lactate (Supplementary Figure 1b), abolished the increased immobility induced by corticosterone treatment in the FST and tail suspension test. In rodents, chronic corticosterone exposure induces anhedonia, a core symptom of depression. ${ }^{31}$ Therefore, we investigated whether L-lactate reversed the anhedonic-like behavior induced by chronic corticosterone treatment. Our data revealed that chronic peripheral administration of L-lactate reversed the corticosterone-induced decrease in saccharin consumption (Figure 3c).

Finally, the effect of peripheral L-lactate administration on depressive-like behavior was investigated in the the open-space forced swim model of depression. This behavioral paradigm induces a chronic depression-like state that responds to chronic but not acute antidepressant treatment. ${ }^{20,32}$ Daily injection of L-lactate for 3 weeks decreased the immobility time in the openspace forced swim model of depression to a similar extent as desipramine (Figure 4a). In contrast to L-lactate, chronic administration of D-lactate did not reduce the immobility time in this behavioral model of depression (Supplementary Figure 1c).

\section{Analysis of target genes regulated by chronic L-lactate} administration

Characterization of the molecular mechanisms underlying the chronic antidepressant-like effects of L-lactate revealed that chronic peripheral administration of L-lactate regulated the expression of a specific group of genes involved in major depression and antidepressant treatment. Thus, chronic peripheral L-lactate administration increased mRNA and protein levels encoding the regulator of serotonin receptors $\mathrm{p} 11,{ }^{33}$ the astrocytic marker $\mathrm{S} 100 \mathrm{\beta}^{1}$ and the transcription factor $\mathrm{Hes}^{34}$ in the hippocampus of animals subjected to the open-space FST compared with vehicle-treated animals (Figures $4 \mathrm{~b}-\mathrm{d}$ ).

In addition to p11, S100 $\beta$ and Hes5, the expression of CAMPspecific phosphodiesterase-4D (PDE4D) and NOS1 was found to be decreased by chronic peripheral administration of L-lactate both at the mRNA and protein levels in the hippocampus of animals subjected to the open-space FST compared with vehicle-treated animals (Figures $4 e$ and $f$ ). Although NOS1AP mRNA levels were decreased by chronic L-lactate administration, NOS1AP expression at the protein level remained unaltered (Figure $4 \mathrm{~g}$ ).

\section{DISCUSSION}

The present set of data shows that peripheral administration of Llactate produces antidepressant-like effects in different animal models of depression that respond to acute or chronic antidepressant treatment. In particular, chronic peripheral L-lactate administration completely reverses the corticosterone-induced anhedonia-like behavior (Figure 3c) and partially restores mobility in the open-space forced swim model of depression (Figure 4a). Importantly, these antidepressant effects of L-lactate, that are similar to those induced by desipramine, are not reproduced by the enantioner D-lactate (Supplementary Figure 1) and do not result from changes in locomotor activity and muscle strength (Supplementary Figure 2).

Acute peripheral administration of L-lactate increases hippocampal extracellular lactate concentration (Figure 1b) and regulates downstream signaling proteins (Figures $2 \mathrm{~b}-\mathrm{d}$ ) and target genes (Figures $2 \mathrm{e}-\mathrm{g}$ ) in the hippocampus. The elevated hippocampal lactate concentration following acute peripheral lactate administration (Figure $1 \mathrm{~b}$ ) is consistent with previous data showing that a net uptake of lactate into the human brain is 

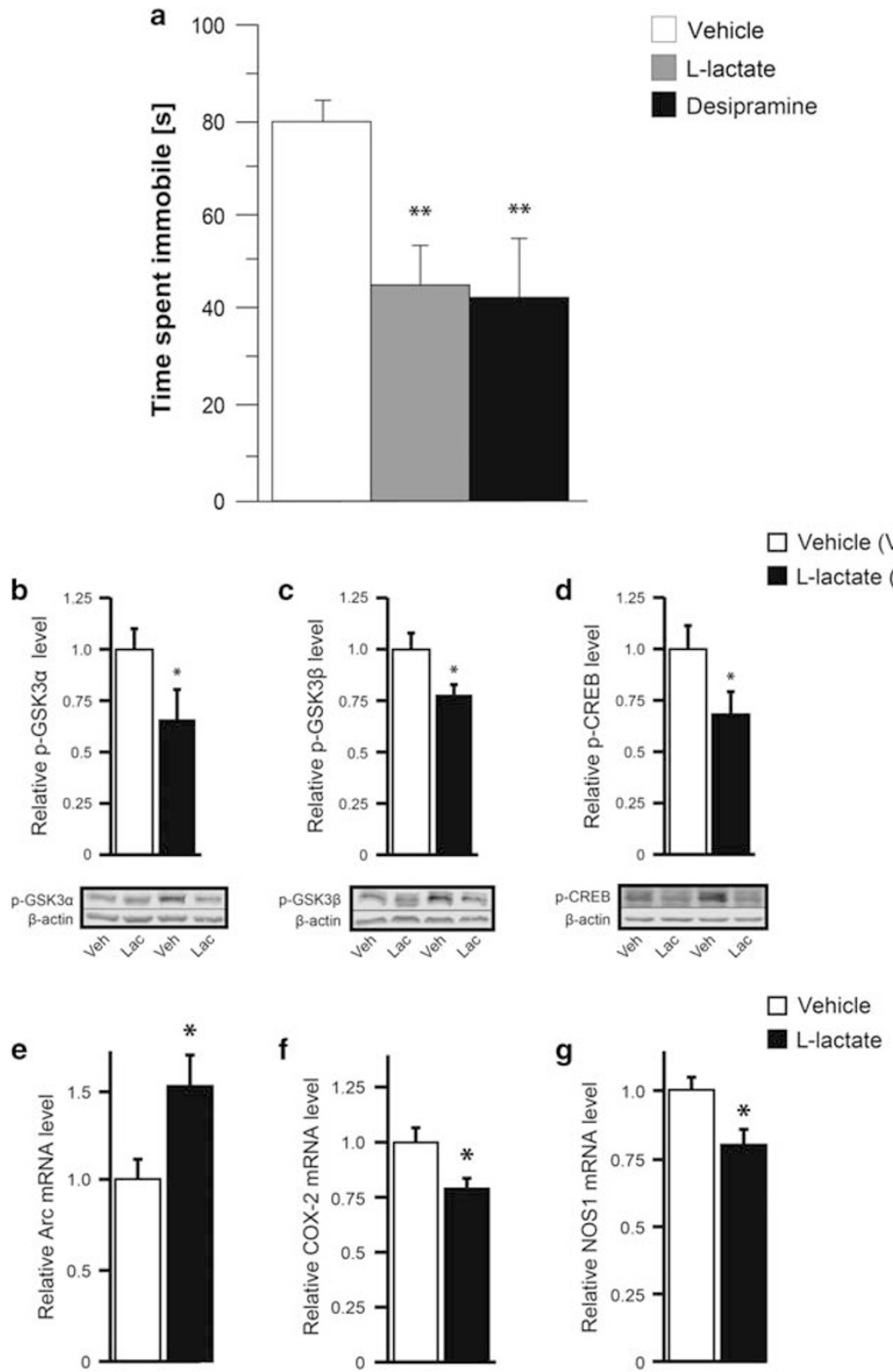

Figure 2. L-Lactate induces antidepressant-like effects in the forced swim test and regulates downstream signaling and target genes. (a) Acute peripheral administration of L-lactate produces antidepressant-like effects in the forced swim test (FST). Mice received a single intraperitoneal injection of vehicle $(0.9 \% \mathrm{NaCl}, n=17)$, L-lactate $\left(1 \mathrm{~g} \mathrm{~kg}^{-1}, n=17\right)$ or desipramine $\left(20 \mathrm{mg} \mathrm{kg}^{-1}, n=12\right)$ and were subjected to behavioral testing $1 \mathrm{~h}$ later. Both L-lactate and desipramine significantly reduced immobility in the FST as analyzed by one-way analysis of variance (ANOVA), followed by Tukey's post hoc test $\left(F_{2,4}=6.564, P<0.05\right)$. Data are the mean \pm s.e.m. ${ }^{* *} P<0.01$ compared with vehicle-treated mice. (b-d) Phosphorylation levels of glycogen synthase kinase-3 $\alpha$ (GSK3 $\alpha$ ), GSK3 $\beta$ and CAMP response element-binding protein (CREB) in the hippocampus were reduced $1 \mathrm{~h}$ after a single intraperitoneal injection of L-lactate, as shown by western blot analysis. Data are the mean \pm s.e. m., $n=10$ mice per group. ${ }^{*} P<0.05$ compared to vehicle-treated mice (Student's $t$-test). (e-g) Quantitative PCR analysis revealed that a single intraperitoneal injection of L-lactate regulated the expression of Arc, cyclooxygenase-2 (COX-2) and nitric oxide synthase 1 (NOS1) mRNAs. Arc mRNA level was increased in the hippocampus of L-lactate- compared with vehicle-treated mice. COX-2 and NOS1 mRNA levels were decreased in the hippocampus of L-lactate- compared with vehicle-treated mice. Data are the mean \pm s.e.m. (vehicle $n=16$, L-lactate $n=17$ ). ${ }^{*} P<0.05$ compared with vehicle-treated mice (Student's $t$-test).

observed when arterial lactate levels increase such as during lactate infusion or intense exercise. ${ }^{35,36}$

Among the genes regulated by a single peripheral injection of L-lactate (Figures $2 \mathrm{e}-\mathrm{g}$ ), Arc is important for synaptic function and dysregulation of Arc expression may lead to cognitive disorders. ${ }^{37}$ Recent data from our laboratory have shown that L-lactate increases the expression of synaptic plasticity-related genes including Arc, c-fos and Zif268 in cortical neurons. ${ }^{11}$ With regard to major depression, the expression of Arc is decreased in the prefrontal cortex of depressed subjects and in the medial prefrontal cortex of mice susceptible to chronic social defeat stress. ${ }^{12}$ Conversely, chronic antidepressant administration and electroconvulsive stimulation upregulate Arc mRNA expression in the hippocampus and parietal cortex. ${ }^{38}$ In addition, administration of the fast-acting antidepressant ketamine induces Arc expression in the rat prefrontal cortex and other cortical regions. ${ }^{39}$ These 
findings support the view that the expression of Arc is downregulated in depressive-like states in human and rodents and is upregulated following antidepressant treatment. In line with this view, the increased expression of Arc in the hippocampus following a single injection of L-lactate (Figure 2e) is likely to be implicated in the acute antidepressant-like effects of L-lactate.

Previous studies indicate that inflammatory processes may be involved in patients suffering from major depression. As proinflammatory cytokines and tumor necrosis factor-a production is increased in depressed patients, ${ }^{40}$ anti-inflammatory treatment should reduce depressive symptoms. In this regard, treatment with the COX-2 inhibitor celecoxib decreases depressive symptoms in depressed patients. ${ }^{41}$ In rodents, chronic treatment with celecoxib reverses chronic unpredictable stress-induced depressive-like behavior through reduction of COX-2 expression. ${ }^{42}$ Collectively, these data suggest that the decreased expression of COX-2 by L-lactate in the hippocampus (Figure $2 f$ ) may contribute to the acute antidepressant actions of L-lactate.

Increasing evidence indicates that inhibition of NOS induces antidepressant-like effects. ${ }^{43}$ In particular, pharmacological inhibition of NOS1 produces antidepressant-like effects in the $\mathrm{FST}^{30}$ and chronic unpredictable mild stress. ${ }^{44}$ Inhibition of NOS1 expression in the hippocampus following acute (Figure $2 \mathrm{~g}$ ) and chronic administration of L-lactate (Figure $4 \mathrm{f}$ ) is consistent with these findings and suggests that the decreased expression of NOS1 is important in mediating the acute and chronic antidepressant-like effects of L-lactate.
Previous studies have provided evidence that dysregulation of GSK3 promotes susceptibility to mood disorders and that inhibition of GSK3 activity reduces depression- and manic-like behaviors. ${ }^{27}$ Interestingly, inhibition of GSK3 phosphorylation by a single administration of L-lactate (Figures $2 \mathrm{~b}$ and c) contrasts with the acute effect of the antidepressant fluoxetine that increases GSK3 phosphorylation in the prefrontal cortex and hippocampus. ${ }^{45}$

The transcription factor CREB is involved in the pathophysiology of depression and its treatment by antidepressants. ${ }^{28}$ Most studies have shown that CREB expression and activity are increased by chronic treatment with antidepressants in rodents and post-mortem human brain. ${ }^{46,47}$ However, acute administration of antidepressants does not affect CREB phosphorylation in the hippocampus. ${ }^{48}$ Interestingly, electroconvulsive shocks, a therapy used for severely depressed patients, activates protein phosphatase $2 \mathrm{~A}$ and reduces GSK3 $\beta$ and CREB phosphorylation, ${ }^{49}$ similarly to what was observed after a single administration of L-lactate (Figures 2c and d).

P11 was initially identified as a binding protein for 5-HTR1B, 5-HTR1D and 5-HTR4 and overexpression of p11 was shown to increase 5-HTR1B and 5-HTR4 expression at the cell surface, thereby amplifying 5-HT signaling. ${ }^{33}$ Levels of $\mathrm{P} 11$ are decreased in the anterior cingulate cortex and nucleus accumbens of depressed patients as well as in a genetic animal model of depression. ${ }^{33}$ Conversely, antidepressants from different classes and electroconvulsive therapy increase p11 levels in the frontal cortex and hippocampus of rodents. ${ }^{33}$ The increased expression of $\mathrm{p} 11$ by
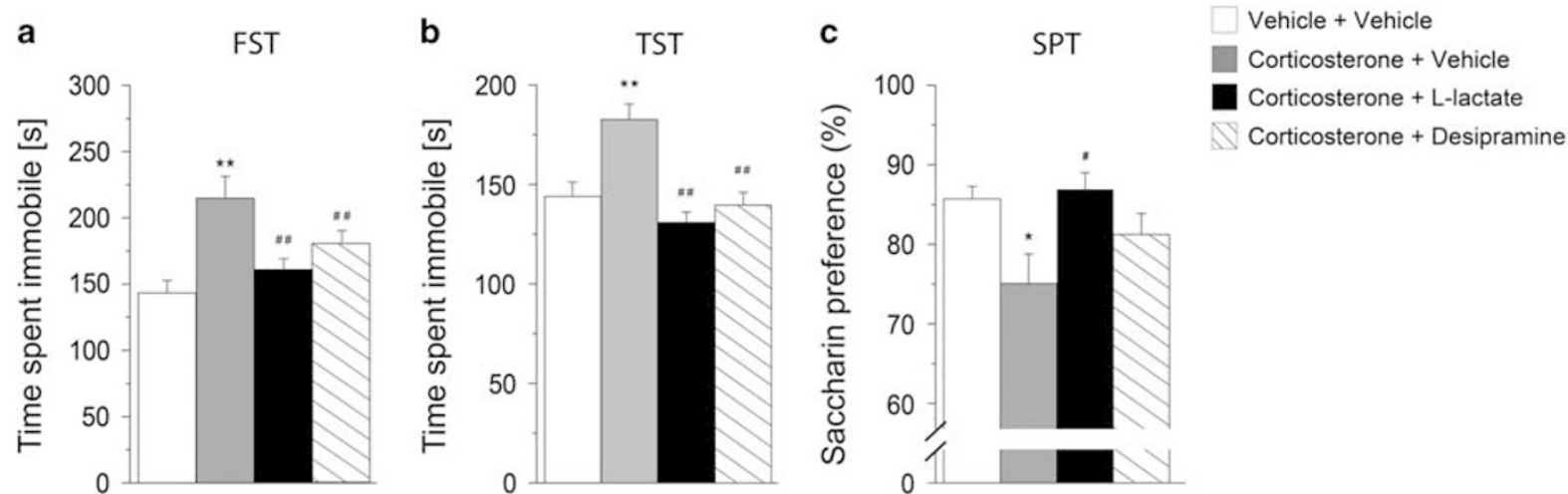

Figure 3. Chronic peripheral administration of L-lactate produces antidepressant-like effects in the chronic corticosterone paradigm. Mice received a single subcutaneous injection of corticosterone $\left(20 \mathrm{mg} \mathrm{kg}^{-1}\right)$ or vehicle ( $2 \%$ dimethyl sulfoxide (DMSO) in sesame oil) on each of 21 consecutive days. Corticosterone-treated mice were given intraperitoneal injections of vehicle $(0.9 \% \mathrm{NaCl})$, L-lactate $\left(1 \mathrm{~g} \mathrm{~kg}{ }^{-1}\right)$ or desipramine $\left(20 \mathrm{mg} \mathrm{kg}^{-1}\right.$ ) daily for 21 days. At $24 \mathrm{~h}$ after the last injection, mice were tested in the forced swim test (FST), tail suspension test (TST) and saccharin preference test (SPT). (a and b) Chronic administration of L-lactate and desipramine $(n=9$ and $n=10$, respectively) abolished the increased immobility induced by corticosterone treatment in the FST $\left(F_{3,45}=15.041\right)$ and TST $\left(F_{3,45}=14.253\right)$. (c) Chronic peripheral administration of L-lactate reversed the corticosterone-induced decrease in saccharin preference $\left(F_{3,33}=4.436\right)$. Data are the mean \pm s.e.m. One-way analysis of variance (ANOVA) followed by Tukey's post hoc test. ${ }^{*} P<0.01$ and ${ }^{*} P<0.05$ compared with vehicle + vehicle-treated mice $(n=10) ;{ }^{\# \#} P<0.01$ and ${ }^{\#} P<0.05$ compared with corticosterone + vehicle-treated mice $(n=8)$.

Figure 4. Chronic peripheral administration of L-lactate produces antidepressant-like effects in the open-space FST and regulates target gene expression. (a) Mice were exposed to the open-space FST according to Stone and Lin. ${ }^{20}$ During pretest (days $\left.1-4\right)$, mice were subjected to four consecutive daily swim sessions. During treatment (days 1-19), mice received daily intraperitoneal administrations of vehicle $(0.9 \%$ NaCl, $n=8)$, L-lactate $\left(1 \mathrm{~g} \mathrm{~kg}^{-1}, n=10\right)$ or desipramine $\left(20 \mathrm{mg} \mathrm{kg}^{-1}, n=10\right)$ and were subjected to a swim session twice a week (at days 2, 5, $9,12,16$ and 19). Two-ways repeated-measures analysis of variance (ANOVA) followed by Bonferroni post hoc test revealed a significant increase in immobility time for all groups after pretest $\left(F_{3,72}=29.377, \# \# \#<0.001\right.$ compared with day 1$)$. Chronic injection of L-lactate and desipramine significantly reduced immobility time as analyzed by Tukey's post hoc test $\left(F_{2,120}=3.961, * P<0.05\right.$ compared with vehicle-treated mice). (b-g) Chronic peripheral L-lactate administration regulates the expression of p11 (b), S100 $\beta$ (c), Hes5 (d), phosphodiesterase-4D (PDE4D) (e), nitric oxide synthase 1 (NOS1) (f) and NOS1AP (g) expression in the hippocampus of animals subjected to the open-space FST. Quantitative PCR and western blot analysis revealed that $\mathrm{p} 11, \mathrm{~S} 100 \beta$ and Hes 5 mRNA and protein levels were increased in the hippocampus of L-lactate- compared with vehicle-treated mice, whereas PDE4D and NOS1 mRNA and protein levels were decreased in the hippocampus of L-lactate- compared with vehicle-treated mice. Data are the mean \pm s.e.m., $n=11$ mice per group. ${ }^{*} P<0.05,{ }^{*} P<0.01$ compared with vehicle-treated mice (Student's t-test). FST, forced swim test. 
L-lactate in the hippocampus of animals subjected to the open-space FST (Figure 4b) is consistent with these studies and supports a role for $\mathrm{p} 11$ in the chronic antidepressant-like effects of L-lactate.

Although brain imaging and post-mortem studies have identified changes in the number and shape of specific neuronal populations in the brain of depressed patients, abundant evidence indicates that structural and functional abnormalities of astrocytes have a major role in the development of depression. ${ }^{1}$ In particular, human post-mortem studies have revealed alterations in the expression of astrocyte markers in different frontolimbic brain

\section{a}

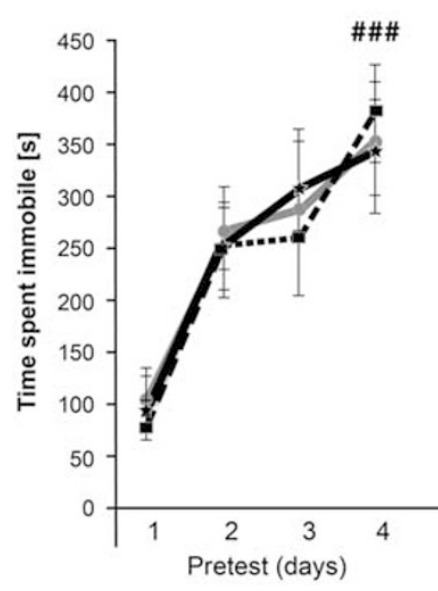

b
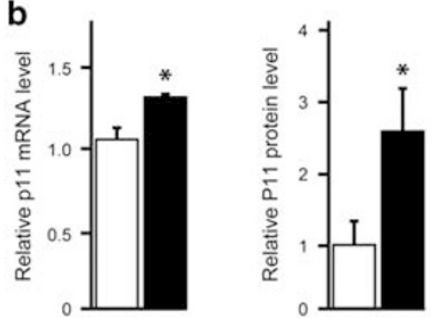

$P 11$
$\beta$-actin
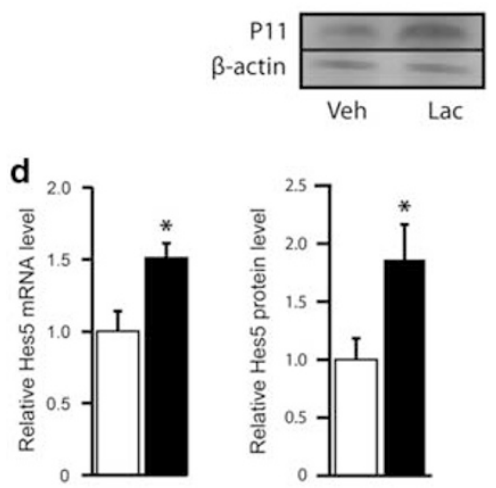

Hes5

$\beta$-actin
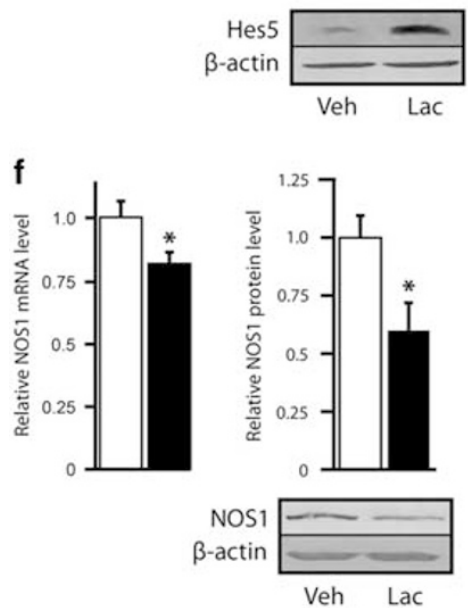
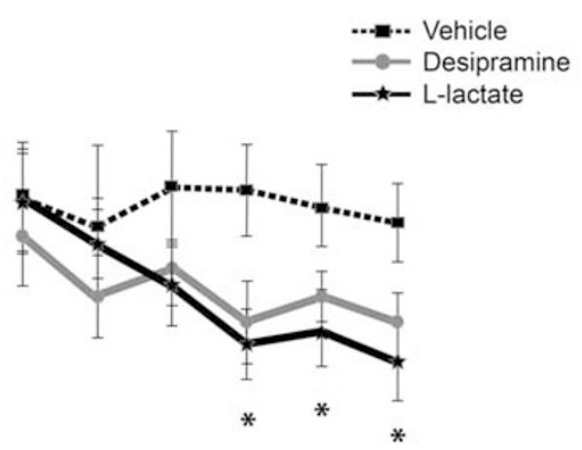

L-lactate
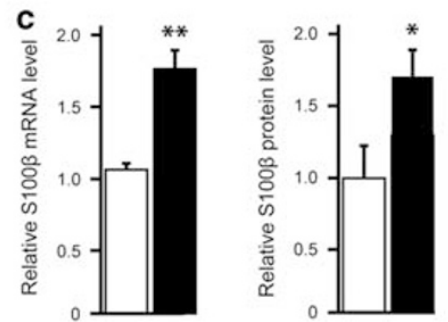

$\mathrm{S} 100 \beta$ $\beta$-actin
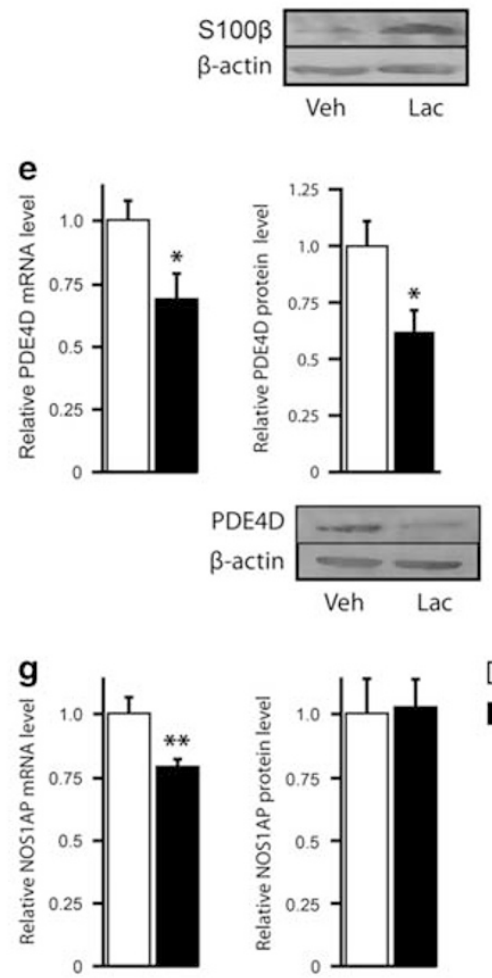

$\square$ Vehicle (Veh)

L-lactate (Lac)

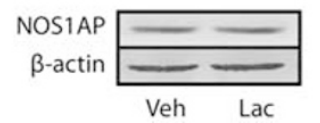


regions. ${ }^{1}$ Among astrocyte markers, the expression of the calciumbinding protein $S 100 \beta$ is reduced in the ventral prefrontal cortex of depressed suicides ${ }^{50}$ and the density of $5100 \beta$-immunopositive astrocytes is decreased in the CA1 pyramidal layer of depressed subjects. $^{51}$ In contrast, chronic treatment with the selective serotonin reuptake inhibitor antidepressant fluoxetine increases $\mathrm{S} 100 \beta$ expression in the rodent hippocampus. ${ }^{52,53}$ Our data showing that L-lactate administration increases $\mathrm{S} 100 \beta$ expression in the hippocampus of animals subjected to the open-space FST (Figure 4c) are in line with these observations, and suggest that $\mathrm{S} 100 \beta$ may be a mediator of the chronic antidepressant-like effects of L-lactate.

Hes5 is a downstream effector of Notch signaling, a pathway that has a central role in regulating hippocampal neurogenesis. ${ }^{54,55}$ Stress, a major risk factor for depression, decreases hippocampal neurogenesis, whereas chronic antidepressant treatment normalizes neurogenesis. ${ }^{56}$ The increased expression of Hes5 by L-lactate (Figure $4 d$ ) in the hippocampus of animals subjected to the open-space FST suggests that stimulation of hippocampal neurogenesis may be involved in the chronic antidepressant-like effects of L-lactate.

Several lines of evidence suggest that dysregulation of CAMPmediated signaling is involved in the pathophysiology of depression. Thus, elevation of intracellular CAMP via pharmacological inhibition of PDE4 enzymes induces antidepressant-like effects in animal models. ${ }^{57,58}$ Further studies have shown that the PDE4D subtype has a pivotal role in the antidepressant-like effects of PDE4 inhibitors. Thus, mice lacking PDE4D ${ }^{59}$ or with reduced expression of PDE4D in the prefrontal cortex ${ }^{60}$ exhibit antidepressant-like behavior. The inhibitory effect of L-lactate on the expression of PDE4D in the hippocampus of animals subjected to the open-space FST (Figure 4e) is consistent with these findings and suggests that reduction of PDE4D expression may contribute to the chronic antidepressant-like effects of L-lactate.

Collectively, data regarding the characterization of the molecular mechanisms underlying the chronic antidepressant effects of L-lactate show that L-lactate acts by regulating the expression of proteins involved in 5-hydroxytryptamine receptor trafficking, astrocyte functions, neurogenesis, NO synthesis and CAMP signaling.

Taken together, these studies identify a previously unrecognized action of L-lactate by which acute and chronic peripheral administration produces antidepressant-like behavioral responses. Peripheral L-lactate injection increases hippocampal lactate levels and regulates downstream signaling molecules and target genes that may contribute to the antidepressant action of L-lactate. Further elucidation of the mechanisms underlying the antidepressant effects of L-lactate may help to identify novel therapeutic targets for the treatment of depression.

\section{CONFLICT OF INTEREST}

The authors declare no conflict of interest.

\section{ACKNOWLEDGMENTS}

We thank Dr I Allaman for critical reading of the manuscript and C Martin for assistance with preliminary experiments. This work was supported by the National Center of Competence in Research (NCCR) Synapsy, the Préfargier Foundation and by funding from King Abdullah University of Science and Technology (KAUST).

\section{AUTHOR CONTRIBUTIONS}

AC, PJM and J-LM conceived the study and designed the experiments. AC and J-LM wrote the manuscript. AC and ME performed most experiments with the help of BB-J, LF, EM and J-MP, AC, ME, MM, BB-J, HF and J-LM analyzed the data.

\section{REFERENCES}

1 Rajkowska G, Stockmeier CA. Astrocyte pathology in major depressive disorder: insights from human postmortem brain tissue. Curr Drug Targets 2013; 14: 1225-1236.

2 Cobb JA, O'Neill K, Milner J, Mahajan GJ, Lawrence TJ, May WL et al. Density of GFAP-immunoreactive astrocytes is decreased in left hippocampi in major depressive disorder. Neuroscience 2016; 316: 209-220.

3 Bélanger M, Allaman I, Magistretti PJ. Brain energy metabolism: focus on astrocyte-neuron metabolic cooperation. Cell Metab 2011; 14: 724-738.

4 Allen NJ. Astrocyte regulation of synaptic behavior. Annu Rev Cell Dev Biol 2014; 30: 439-463.

5 Pellerin L, Magistretti PJ. Sweet sixteen for ANLS. J Cereb Blood Flow Metab 2012; 32: $1152-1166$.

6 Magistretti PJ, Manthorpe M, Bloom FE, Varon S. Functional receptors for vasoactive intestinal polypeptide in cultured astroglia from neonatal rat brain. Regul Pept 1983; 6: 71-80.

7 Walls $A B$, Heimbürger CM, Bouman SD, Schousboe A, Waagepetersen HS. Robust glycogen shunt activity in astrocytes: effects of glutamatergic and adrenergic agents. Neuroscience 2009; 158: 284-292.

8 Mosienko V, Teschemacher AG, Kasparov S. Is L-lactate a novel signaling molecule in the brain? J Cereb Blood Flow Metab 2015; 35: 1069-1075.

9 Suzuki A, Stern SA, Bozdagi O, Huntley GW, Walker RH, Magistretti PJ et al. Astrocyte-neuron lactate transport is required for long-term memory formation. Cell 2011; 144: 810-823.

10 Boury-Jamot B, Carrard A, Martin JL, Halfon O, Magistretti PJ, Boutrel B. Disrupting astrocyte-neuron lactate transfer persistently reduces conditioned responses to cocaine. Mol Psychiatry 2015; 21: 1070-1076.

11 Yang J, Ruchti E, Petit J-M, Jourdain P, Grenningloh G, Allaman I et al. Lactate promotes plasticity gene expression by potentiating NMDA signaling in neurons. Proc Natl Acad Sci USA 2014; 111: 12228-12233.

12 Covington HE, Lobo MK, Maze I, Vialou V, Hyman JM, Zaman S et al. Antidepressant effect of optogenetic stimulation of the medial prefrontal cortex. J Neurosci Off J Soc Neurosci 2010; 30: 16082-16090.

13 Slattery DA, Morrow JA, Hudson AL, Hill DR, Nutt DJ, Henry B. Comparison of alterations in c-fos and Egr-1 (zif268) expression throughout the rat brain following acute administration of different classes of antidepressant compounds. Neuropsychopharmacology 2005; 30: 1278-1287.

14 Dahmen N, Fehr C, Reuss S, Hiemke C. Stimulation of immediate early gene expression by desipramine in rat brain. Biol Psychiatry 1997; 42: 317-323.

15 Duman RS, Monteggia LM. A neurotrophic model for stress-related mood disorders. Biol Psychiatry 2006; 59: 1116-1127.

16 Chen B, Dowlatshahi D, MacQueen GM, Wang J-F, Young LT. Increased hippocampal bdnf immunoreactivity in subjects treated with antidepressant medication. Biol Psychiatry 2001; 50: 260-265.

17 Licznerski P, Duman RS. Remodeling of axo-spinous synapses in the pathophysiology and treatment of depression. Neuroscience 2013; 251: 33-50.

18 Duman RS, Aghajanian GK, Sanacora G, Krystal JH. Synaptic plasticity and depression: new insights from stress and rapid-acting antidepressants. Nat Med 2016; 22: 238-249.

19 Schmidt HD, Duman RS. Peripheral BDNF produces antidepressant-like effects in cellular and behavioral models. Neuropsychopharmacology 2010; 35: 2378-2391.

20 Stone EA, Lin Y. Open-space forced swim model of depression for mice. Curr Protoc Neurosci 2011; Chapter 9: Unit 9.36.

21 Zhao Y, Ma R, Shen J, Su H, Xing D, Du L. A mouse model of depression induced by repeated corticosterone injections. Eur J Pharmacol 2008; 581: 113-120.

22 Oh S-L, Chang H, Kim H-J, Kim Y-A, Kim D-S, Ho S-H et al. Effect of HX108-CS supplementation on exercise capacity and lactate accumulation after highintensity exercise. J Int Soc Sports Nutr 2013; 10: 21.

23 Pederson BA, Cope CR, Schroeder JM, Smith MW, Irimia JM, Thurberg BL et al. Exercise capacity of mice genetically lacking muscle glycogen synthase in mice, muscle glycogen is not essential for exercise. J Biol Chem 2005; 280: 17260-17265.

24 Elekesa O, Venema K, Postema F, Dringen R, Hamprecht B, Korf J. Evidence that stress activates glial lactate formation in vivo assessed with rat hippocampus lactography. Neurosci Lett 1996; 208: 69-72.

25 De Bruin LA, Schasfoort EM, Steffens AB, Korf J. Effects of stress and exercise on rat hippocampus and striatum extracellular lactate. Am J Physiol 1990; 259: R773-R779.

26 Nestler EJ, Hyman SE. Animal models of neuropsychiatric disorders. Nat Neurosci 2010; 13: 1161-1169.

27 Jope RS. Glycogen synthase kinase-3 in the etiology and treatment of mood disorders. Front Mol Neurosci 2011; 4: 16.

28 Blendy JA. The role of CREB in depression and antidepressant treatment. Biol Psychiatry 2006; 59: 1144-1150. 
29 Dantzer R, O'Connor JC, Freund GG, Johnson RW, Kelley KW. From inflammation to sickness and depression: when the immune system subjugates the brain. Nat Rev Neurosci 2008; 9: 46-56.

30 Joca SRL, Guimarães FS. Inhibition of neuronal nitric oxide synthase in the rat hippocampus induces antidepressant-like effects. Psychopharmacology (Berl) 2006; 185: 298-305.

31 Sterner EY, Kalynchuk LE. Behavioral and neurobiological consequences of prolonged glucocorticoid exposure in rats: relevance to depression. Prog Neuropsychopharmacol Biol Psychiatry 2010; 34: 777-790.

32 Stone EA, Lin Y, Quartermain D. Evaluation of the repeated open-space swim model of depression in the mouse. Pharmacol Biochem Behav 2008; 91: 190-195.

33 Svenningsson P, Kim Y, Warner-Schmidt J, Oh Y-S, Greengard P. P11 and its role in depression and therapeutic responses to antidepressants. Nat Rev Neurosci 2013; 14: $673-680$.

34 Kobayashi T, Kageyama R. Chapter seven-expression dynamics and functions of Hes factors in development and diseases. In: Taneja R (ed). Current Topics in Developmental Biology. Academic Press: New York, NY, 2014, pp 263-283.

35 van Hall G, Strømstad M, Rasmussen P, Jans $\varnothing$, Zaar M, Gam C et al. Blood lactate is an important energy source for the human brain. J Cereb Blood Flow Metab 2009; 29: 1121-1129.

36 Quistorff B, Secher NH, Lieshout JJV. Lactate fuels the human brain during exercise. Faseb J 2008; 22: 3443-3449.

37 Shepherd JD, Bear MF. New views of Arc, a master regulator of synaptic plasticity. Nat Neurosci 2011; 14: 279-284.

38 Molteni R, Calabrese F, Mancini M, Racagni G, Riva MA. Basal and stress-induced modulation of activity-regulated cytoskeletal associated protein (Arc) in the rat brain following duloxetine treatment. Psychopharmacology (Berl) 2008; 201: 285-292.

39 Li N, Lee B, Liu R-J, Banasr M, Dwyer JM, Iwata M et al. mTOR-dependent synapse formation underlies the rapid antidepressant effects of NMDA antagonists. Science 2010; 329: 959-964.

40 Miller $\mathrm{AH}$, Maletic V, Raison CL. Inflammation and its discontents: the role of cytokines in the pathophysiology of major depression. Biol Psychiatry 2009; 65: 732-741.

41 Müller N, Schwarz MJ, Dehning S, Douhe A, Cerovecki A, Goldstein-Müller B et al. The cyclooxygenase-2 inhibitor celecoxib has therapeutic effects in major depression: results of a double-blind, randomized, placebo controlled, add-on pilot study to reboxetine. Mol Psychiatry 2006; 11: 680-684.

42 Guo J-Y, Li C-Y, Ruan Y-P, Sun M, Qi X-L, Zhao B-S et al. Chronic treatment with celecoxib reverses chronic unpredictable stress-induced depressive-like behavior via reducing cyclooxygenase-2 expression in rat brain. Eur J Pharmacol 2009; 612: 54-60.

43 Dhir A, Kulkarni SK. Nitric oxide and major depression. Nitric Oxide 2011; 24: 125-131.

44 Yazir Y, Utkan T, Aricioglu F. Inhibition of neuronal nitric oxide synthase and soluble guanylate cyclase prevents depression-like behaviour in rats exposed to chronic unpredictable mild stress. Basic Clin Pharmacol Toxicol 2012; 111: 154-160.

45 Li X, Zhu W, Roh M-S, Friedman AB, Rosborough K, Jope RS. In vivo regulation of glycogen synthase kinase-3 $\beta$ (GSK3 $\beta$ ) by serotonergic activity in mouse brain Neuropsychopharmacol Off Publ Am Coll Neuropsychopharmacol 2004; 29: 1426-1431.

46 Nibuya M, Nestler EJ, Duman RS. Chronic antidepressant administration increases the expression of CAMP response element binding protein (CREB) in rat hippocampus. J Neurosci 1996; 16: 2365-2372.
47 Young LT, Dowlatshahi D, MacQueen GM, Wang JF. Increased temporal cortex CREB concentrations and antidepressant treatment in major depression. Lancet 1998; 352: 1754-1755.

48 Tiraboschi E, Tardito D, Kasahara J, Moraschi S, Pruneri P, Gennarelli M et al. Selective phosphorylation of nuclear CREB by fluoxetine is linked to activation of CaM kinase IV and MAP kinase cascades. Neuropsychopharmacology 2004; 29: 1831-1840.

49 Kang UG, Jeon WJ, Kim Y, Chung CK, Park JB, Juhnn YS et al. Transient activation of protein phosphatase $2 \mathrm{~A}$ induced by electroconvulsive shock in the rat frontal cortex. Neurosci Lett 2005; 390: 171-175.

50 Klempan TA, Sequeira A, Canetti L, Lalovic A, Ernst C, ffrench-Mullen J et al. Altered expression of genes involved in ATP biosynthesis and GABAergic neurotransmission in the ventral prefrontal cortex of suicides with and without major depression. Mol Psychiatry 2007; 14: 175-189.

51 Gos T, Schroeter ML, Lessel W, Bernstein H-G, Dobrowolny $\mathrm{H}$, Schiltz $\mathrm{K}$ et al. S100B-immunopositive astrocytes and oligodendrocytes in the hippocampus are differentially afflicted in unipolar and bipolar depression: a postmortem study. J Psychiatr Res 2013; 47: 1694-1699.

52 Akhisaroglu M, Manev R, Akhisaroglu E, Uz T, Manev H. Both aging and chronic fluoxetine increase S100B content in the mouse hippocampus. Neuroreport 2003; 14: $1471-1473$.

53 Bock N, Koc E, Alter H, Roessner V, Becker A, Rothenberger A et al. Chronic fluoxetine treatment changes $\mathrm{S} 100 \mathrm{~B}$ expression during postnatal rat brain development. J Child Adolesc Psychopharmacol 2013; 23: 481-489.

54 Breunig JJ, Silbereis J, Vaccarino FM, Šestan N, Rakic P. Notch regulates cell fate and dendrite morphology of newborn neurons in the postnatal dentate gyrus. Proc Natl Acad Sci USA 2007; 104: 20558-20563.

55 Ables JL, DeCarolis NA, Johnson MA, Rivera PD, Gao Z, Cooper DC et al. Notch1 is required for maintenance of the reservoir of adult hippocampal stem cells. J Neurosci 2010; 30: 10484-10492.

56 Malberg JE, Eisch AJ, Nestler EJ, Duman RS. Chronic antidepressant treatment increases neurogenesis in adult rat hippocampus. J Neurosci 2000; 20: 9104-9110.

57 O'Donnell JM, Zhang H-T. Antidepressant effects of inhibitors of CAMP phosphodiesterase (PDE4). Trends Pharmacol Sci 2004; 25: 158-163.

58 Zhang H-T. Cyclic AMP-specific phosphodiesterase-4 as a target for the development of antidepressant drugs. Curr Pharm Des 2009; 15: 1688-1698.

59 Zhang H-T, Huang Y, Jin S-LC, Frith SA, Suvarna N, Conti M et al. Antidepressantlike profile and reduced sensitivity to rolipram in mice deficient in the PDE4D phosphodiesterase enzyme. Neuropsychopharmacology 2002; 27: 587-595.

60 Wang Z-Z, Zhang Y, Liu Y-Q, Zhao N, Zhang Y-Z, Yuan L et al. RNA interferencemediated phosphodiesterase $4 \mathrm{D}$ splice variants knock-down in the prefrontal cortex produces antidepressant-like and cognition-enhancing effects. Br J Pharmacol 2013; 168: 1001-1014.

This work is licensed under a Creative Commons Attribution 4.0 International License. The images or other third party material in this article are included in the article's Creative Commons license, unless indicated otherwise in the credit line; if the material is not included under the Creative Commons license, users will need to obtain permission from the license holder to reproduce the material. To view a copy of this license, visit http://creativecommons.org/licenses/ by/4.0/

(c) The Author(s) 2018

Supplementary Information accompanies the paper on the Molecular Psychiatry website (http://www.nature.com/mp) 